\title{
Prevalence of Dementia and Its Correlates among Participants in the National Early Dementia Detection Program during 2006-2009
}

\author{
Moon-Doo Kim ${ }^{1} \bowtie$, Joon-Hyuk Park', Chang-In Lee ${ }^{1}$, Na-Ri Kang ${ }^{1}$, Jae-Sung Ryu', \\ Bong-Hee Jeon ${ }^{1}$, Ki-Woong Kim², Won-Myong Bahk ${ }^{3}$, Bo-Hyun Yoon ${ }^{4}$, \\ Seunghee Won ${ }^{5}$, Jun Hwa Lee ${ }^{6}$, Duk-Soo Kim ${ }^{7}$ and Seong-Chul Hong ${ }^{8}$ \\ ${ }^{1}$ Department of Psychiatry and Institute of Medical Science, Jeju National University School of Medicine, Jeju, Korea \\ ${ }^{2}$ Department of Neuropsychiatry, Seoul National University Bundang Hospital, Seongnam, Korea \\ ${ }^{3}$ Department of Psychiatry, College of Medicine, The Catholic University of Korea, Seoul, Korea \\ ${ }^{4}$ Department of Psychiatry, Naju National Hospital, Naju, Korea \\ ${ }^{5}$ Department of Psychiatry, Kyungpook National University Hospital, Daegu, Korea \\ ${ }^{6}$ Department of Pediatrics, Samsung Changwon Hospital, Sungkyunkwan University School of Medicine, Changwon, Korea \\ ${ }^{7}$ Department of Chemistry, Jeju National University College of Natural Science, Jeju, Korea \\ ${ }^{8}$ Departments of Preventive Medicine and Institute of Medical Science, Jeju National University School of Medicine, Jeju, Korea
}

Objective To investigate the prevalence of dementia and its correlates among people with poor socioeconomic status, poor social support systems, and poor performance on the Korean version of the Mini-Mental Status Exam (MMSE-KC).

Methods We used 2006-2009 data of the National Early Dementia Detection Program (NEDDP) conducted on Jeju Island. This program included all residents $>65$ years old who were receiving financial assistance. We examined those who performed poorly (standard deviation from the norm of <-1.5) on the MMSE-KC administered as part of the NEDDP, using age-, gender-, and education-adjusted norms for Korean elders. A total of 1708 people were included in this category.

Results The prevalence of dementia in this group was $20.5 \%$. Multivariate logistic regression analysis revealed that the following factors were statistically significantly associated with dementia: age of 80 or older, no education, nursing home residence, and depression.

Conclusion The prevalence of dementia is very high among those with lower MMSE-KC scores, and significant correlates include older age, no education, living in a nursing home, and depression. Enhancing lifetime education to improve individuals' cognitive reserves by providing intellectually challenging activities, encouraging living at home rather than in a nursing home, and preventing and treating depression in its early phase could reduce the prevalence of dementia in this population.

Psychiatry Investig 2012;9:134-142

Key Words Dementia, Prevalence, Correlates, MMSE-KC.

\section{INTRODUCTION}

Korea has a rapidly aging society due to a low birth rate and increasing longevity. The proportion of Koreans over the age of 65 years was $7.2 \%$ in 2000 and $9.1 \%$ in $2005 .^{1}$ In addition, es-

Received: December 9, 2011 Revised: December 20, 2011 Accepted: December 30, 2011 Available online: April 30, 2012

$\triangle$ Correspondence: Moon-Doo Kim, MD, PhD

Department of Psychiatry, Jeju National University School of Medicine, 15 Aran 13-gil, Jeju 690-756, Korea

Tel: +82-64-717-1234, Fax: +82-64-717-1849

E-mail: mdkim66@jejunu.ac.kr

(a) This is an Open Access article distributed under the terms of the Creative Commons Attribution Non-Commercial License (http://creativecommons.org/licenses/bync/3.0) which permits unrestricted non-commercial use, distribution, and reproduction in any medium, provided the original work is properly cited. timates based on population data predict that $14.5 \%$ of Koreans will be over the age of 65 years by 2018 and that by 2026, the percentage will be $20.8 \%{ }^{2}$ The speed at which Korean society is aging is much more rapid than that of any other developed country, ${ }^{3}$ and it is projected to be among the fastest in the world. Korea will replace Italy as having the world's second highest proportion of elderly by 2050 .

Due to this rapidly aging population and the progressive Westernization of lifestyles in Korea, dementia has emerged as a major health problem in Korea. ${ }^{4,5}$ Estimates of the prevalence of dementia in Korea range from $7.0 \%$ to $13.1 \% .3,{ }^{6-9}$ Recently, Kim et al. ${ }^{9}$ predicted that the number of dementia patients will double every 20 years until 2050 in Korea and the dementia pa- 
tient population will skyrocket from 470000 in 2010 to 1140000 by the year 2030 and to 2130000 by the year 2050. Furthermore, they reported that the prevalence of dementia in Korea is higher than in Western countries and in other Asian countries.

The rapid growth of the elderly population and of the population with dementia will impose significant economic and psychosocial burdens on caregivers and societies, likely posing major problems. In the US alone, Alzheimer's disease (AD), the most frequent cause of dementia, is associated with an estimated health care cost of US $\$ 172$ billion per year. ${ }^{10}$ The cost of dementia in Korea was estimated at between US\$3 and US\$7 billion in 2004, ${ }^{8}$ totaling $0.446-1.040 \%$ of the Korean GDP (US\$673.1 billion). ${ }^{11}$ Families of dementia patients also suffer heavy psychological, physical, and economic burdens. ${ }^{12,13}$

To reduce these societal and individual burdens, prevention, early detection, and early treatment may be the most important steps to take. Many studies designed to identify risk factors and correlates of dementia and programs for the early detection and treatment of dementia patients in the general population have been reported. But few, if any, have addressed the portion of the aging population characterized by low socioeconomic status and poor cognitive function (as assessed, for example, by low scores on the Korean version of the Mini-Mental Status Exam, MMSE-KC), who are often at high risk for dementia.

This group is very important because they are on the verge of developing dementia. Preventing dementia in this group is, in a sense, more important than addressing it among the general population. Therefore, we investigated the prevalence of dementia and its correlates among people of low socioeconomic status and with poor social support systems who live on Jeju Island, Korea.

Jeju Island has some advantages for the study of dementia because of the restricted interchange of its population with the mainland. In addition, the island has a greater proportion of aged individuals (10.4\% of the total population in 2005 were over 65 years of age), with those over 80 years of age comprising $8.0 \%$ of the total aged population, the highest among all provinces of Korea. ${ }^{1}$

\section{METHODS}

\section{Subjects and research period}

We used 2006-2009 Jeju Island data from the National Early Dementia Detection Program (NEDDP), which covers all of the economically poor elderly living on Jeju island. This program included all of the residents over the age of 65 who were recipients of financial assistance programs. In 2009, this population included about 5000 people.

This study examined those who showed poor performance [standard deviation (SD) from the norm of <-1.5] on the MMSE-KC, ${ }^{14}$ administered through the NEDDP, using age-, gender-, and education-adjusted norms for Korean elders. ${ }^{15}$ All who agreed to participate in this research were included, resulting in a total of 1708 participants. This study was approved by the Institutional Review Board at Jeju National University Hospital, Jeju, Korea.

\section{Evaluation}

\section{Sociodemographic factors}

A semi-structured interview addressing demographic characteristics (age, sex, education, residence, living arrangement, marital status, economic status, etc.) and history of head trauma, presence of depression, and number of medical illnesses was conducted. If the participant alone could not give enough information, reliable informants (spouse, child, other relatives, and close friends, in that order) were interviewed as well.

\section{Diagnosis of dementia}

Dementia was defined according to the diagnostic criteria of the Diagnostic and Statistical Manual of Mental Disorders, Fourth Edition (DSM-IV). ${ }^{16}$

A face-to-face standardized diagnostic interview and physical and neurological examinations were administered to each subject using the Korean version of the Consortium to Establish a Registry for Alzheimer's Disease Assessment Packet (CERAD-K) and Clinical Assessment Battery (CERAD-K-C) ${ }^{14}$ Geriatric psychiatrists, who were certified in CERAD-K Clinical Assessment Battery (CERAD-K-C) administration by the CERAD-K headquarters, administered the tests. The CERADK Neuropsychological Assessment Battery (CERAD-K-N) $)^{14,15}$ was also administered by neuropsychologists or trained research nurses. The CERAD-K-N consists of nine neuropsychological tests: the verbal fluency test, 15-item Boston Naming Test, MMSE-KC, word-list memory test, constructional praxis test, word-list recall test, word-list recognition test, constructional recall test, and trail-making test. All instruments were validated in the Korean population. We did not classify subtypes of dementia due to the large number of subjects and the screening nature of the NEDDP.

\section{Diagnosis of depression}

The Korean version of the Geriatric Depression-Scale Short form (SGDS-K) ${ }^{17}$ was used to screen for depression. Final diagnosis was made by two psychiatrists according to DSM-IV diagnostic criteria.

\section{Statistical analysis}

We identified the prevalence of dementia among these sub- 
jects according to each factor: age, sex, education, residence, living arrangement, marital status, economic status, presence of head trauma, presence of depression, and number of medical illnesses.

We then performed multiple logistic regression analysis using the statistically significant independent variables, with dementia as the dependent variable. We determined the odds ratio (OR) and 95\% confidence intervals (95\% CI) for each of the independent variables. SPSS (version 12.0) software was used for all analyses, with the level of significance defined as $\mathrm{p} \leq 0.05$.

\section{RESULTS}

\section{Characteristics of participants}

The sample consisted of 1708 community- and nursing homedwelling Koreans, including 1220 women and 488 men, with an average age of $78(\mathrm{SD}=7.2)$ years. The overall mean years of education was 3.3 ( $\mathrm{SD}=4.2$; men: $7.0, \mathrm{SD}=4.2$; women: $1.8, \mathrm{SD}=$ 3.1), and the overall mean MMSE-KC score was 15.9 ( $\mathrm{SD}=5.8$; men: 19.6, $\mathrm{SD}=5.2$; women: $14.4, \mathrm{SD}=5.4)$.

Statistically significant sex differences in age distribution, ed-

Table 1. Characteristics of participants

\begin{tabular}{|c|c|c|c|c|c|c|c|}
\hline \multirow{2}{*}{ Variable } & \multirow{2}{*}{ Level } & Men & 488 & Women & 1220 & Total & 1708 \\
\hline & & $\mathrm{N}$ & $\%$ & $\mathrm{~N}$ & $\%$ & $\mathrm{~N}$ & $\%$ \\
\hline \multirow[t]{5}{*}{ Age* } & $65-69$ & 79 & 16.2 & 143 & 11.7 & 222 & 13.0 \\
\hline & $70-74$ & 164 & 33.6 & 225 & 18.4 & 389 & 22.8 \\
\hline & $75-79$ & 148 & 30.3 & 277 & 22.7 & 425 & 24.9 \\
\hline & $80-84$ & 50 & 10.2 & 265 & 21.7 & 315 & 18.4 \\
\hline & $85+$ & 47 & 9.6 & 310 & 25.4 & 357 & 20.9 \\
\hline \multirow[t]{3}{*}{ Education* } & 7 years+ & 227 & 46.5 & 86 & 7.1 & 313 & 18.3 \\
\hline & 1-6 years & 190 & 38.9 & 315 & 25.9 & 505 & 29.6 \\
\hline & None & 71 & 14.5 & 817 & 67.1 & 888 & 52.1 \\
\hline \multirow[t]{2}{*}{ Residence* } & Urban & 278 & 58.4 & 489 & 40.7 & 767 & 45.7 \\
\hline & Rural & 198 & 41.6 & 713 & 59.3 & 911 & 54.3 \\
\hline \multirow[t]{4}{*}{ Living arrangement* } & With spouse & 295 & 60.6 & 242 & 20.0 & 537 & 31.6 \\
\hline & With others & 35 & 7.2 & 270 & 22.3 & 305 & 18.0 \\
\hline & Alone & 103 & 21.1 & 558 & 46.1 & 661 & 39.0 \\
\hline & Nursing home & 54 & 11.1 & 140 & 11.6 & 194 & 11.4 \\
\hline \multirow[t]{3}{*}{ Marital status* } & Married & 306 & 62.8 & 247 & 20.3 & 553 & 32.4 \\
\hline & Bereaved & 116 & 23.8 & 899 & 73.8 & 1015 & 59.5 \\
\hline & Others & 65 & 13.3 & 72 & 5.9 & 137 & 8.0 \\
\hline \multirow[t]{2}{*}{ Economic status* } & Not disadvantaged & 37 & 7.6 & 25 & 2.1 & 62 & 3.7 \\
\hline & Disadvantaged ${ }^{* *}$ & 449 & 92.4 & 1184 & 97.9 & 1633 & 96.3 \\
\hline \multirow[t]{2}{*}{ head trauma* } & No & 484 & 99.2 & 1219 & 99.9 & 1703 & 99.7 \\
\hline & Yes $^{\dagger}$ & 4 & 0.8 & 1 & 0.1 & 5 & 0.3 \\
\hline \multirow[t]{2}{*}{ Depression } & No & 398 & 81.6 & 977 & 80.1 & 1375 & 80.5 \\
\hline & Yes $^{\ddagger}$ & 90 & 18.4 & 243 & 19.9 & 333 & 19.5 \\
\hline \multirow[t]{4}{*}{ No of medical disease } & 0 & 120 & 33.8 & 282 & 34.0 & 402 & 33.9 \\
\hline & 1 & 129 & 36.3 & 343 & 41.3 & 472 & 39.8 \\
\hline & 2 & 83 & 23.4 & 168 & 20.2 & 251 & 21.2 \\
\hline & $3+$ & 23 & 6.5 & 37 & 4.5 & 60 & 5.1 \\
\hline Continuous variables & & Mean & $\mathrm{SD}$ & Mean & $\mathrm{SD}$ & Mean & $\mathrm{SD}$ \\
\hline Age* & & 75.3 & 6.0 & 79.1 & 7.4 & 78.0 & 7.2 \\
\hline Education years* & & 7.0 & 4.2 & 1.8 & 3.1 & 4.2 & 1.8 \\
\hline MMSE-KC score* & & 19.6 & 5.2 & 14.4 & 5.4 & 15.9 & 5.8 \\
\hline
\end{tabular}

${ }^{*} \mathrm{p}<0.05,{ }^{* *}$ lower than minimum cost of living, ${ }^{\dagger}$ presence of previous head trauma, with loss of consciousness exceeding 10 minutes, $\ddagger_{\text {screened }}$ by SGDS-K $\geq 8$ and diagnosed by two psychiatrists. MMSE-KC: Mini-Mental Status Examination in the Korean Version of the CERAD Assessment Packet 
ucation, residence, living arrangement, marital status, economic status, and presence of head trauma history (all p-values $<0.05$ ) were found; only depression and number of medical illnesses showed no sex differences (Table 1).

\section{Prevalence and OR of dementia}

We examined the prevalence of dementia according to various levels of variables and calculated crude and age- and sexadjusted ORs. Of the 1708 participants who completed the evaluation, 318 (20.5\%) were diagnosed with dementia, including 72 (17.3\%) men and 246 (21.7\%) women. The prevalence was not statistically different between the sexes $(\mathrm{p}=0.055)$. The prevalence of dementia showed an increasing trend by age, being $14.7 \%$ for 65 - to 69 -year-olds, $15.4 \%$ for 70 - to 74 -year-olds, $25.7 \%$ for 80 - to 84 -year-olds, and $28.0 \%$ for $\geq 85$-year-olds. Regarding education, the prevalence of dementia was $26.6 \%$ in the no-education group, $13.7 \%$ in the group with 1-6 years of education, and $12.4 \%$ among those with 7 years of education and more. The prevalence of dementia among those living in a nursing home was $46.1 \%$, and that among subjects with a history of head trauma and depression was $60 \%$ and $23.4 \%$, respectively.

The $85+$ years age group $(\mathrm{OR}=2.204,95 \% \mathrm{CI} 1.378-3.526)$ was more likely to have dementia than the $65-69$ years age group. Those in the no-education group (OR=2.621, 95\% CI 1.6064.277) were more likely to have dementia than those with 7 years education or more. Persons living in a nursing home ( $\mathrm{OR}=3.969$, 95\% CI 2.649-5.947) were more likely to have dementia than those living with a spouse. Those who had a history of head trau$\mathrm{ma}(\mathrm{OR}=6.210,95 \% \mathrm{CI} 1.022-37.744)$ were more likely to have dementia than those without such a history. However, persons with depression ( $\mathrm{OR}=1.258,95 \%$ CI 0.929-1.703) were not more likely to have dementia than those without depression. There were no statistically significant differences according to marital status, residence, economic status, presence of depression, and number of medical diseases. In summary, our univariate logistic analyses indicate that older age ( $80-84$ and $\geq 85$ years of age), no education, nursing home residence, and presence of head trauma history are associated with dementia (Table 2).

\section{Multiple logistic regression analysis}

Table 3 shows the results of the multiple logistic regression analysis. The results indicate that the following factors were statistically significantly associated with dementia: age 80-84 $(\mathrm{OR}=2.132,95 \% \mathrm{CI} 1.163-3.908)$ or $\geq 85$ years $(\mathrm{OR}=1.963,95 \%$ CI 1.065-3.617), no education ( $\mathrm{OR}=2.078,95 \%$ CI 1.145-3.771), nursing home residence ( $\mathrm{OR}=5.630,95 \% \mathrm{CI} 2.107-15.044)$, and depression (OR=1.586, 95\% CI 1.089-2.309).

Marital status, urban/rural residence, socioeconomic status, and number of medical illnesses were not significantly correlated with dementia after controlling for the confounding influence of age, sex, education, living arrangement, presence of depression, and number of medical illnesses.

\section{DISCUSSION}

In a previous study on the general Korean population, the prevalence of dementia was estimated as $8.1 \%{ }^{9}$ In the present study, which focused on a subpopulation of Korea, it was $20.5 \%$, much higher. This could be explained by the characteristics of the subjects in the present study, namely, a population with a large proportion of older persons with no formal education (52.1\%), with lower socioeconomic status, lower MMSE-KC scores, and a larger proportion of nursing home residents (11.6\%) compared to the general population. This result is partially consistent with the results from Hamid et al..$^{18}$ and Wimo et al., ${ }^{19}$ who noted that the prevalence of dementia is 3-4 times higher in developing countries than in developed countries. They suggested that the lack of formal education is a major contributor to higher overall dementia prevalence. Among our subjects, $52.1 \%$ had no education, which is consistent with their conclusion.

We included subjects who had an MMSE-KC score below $-1.5 \mathrm{SD}$ of the mean compared to age-, sex-, and educationadjusted norms for Korean elders. ${ }^{15}$ Kim et al. ${ }^{9}$ investigated the prevalence of dementia in a nationwide Korean sample using MMSE-KC. They assigned scores of $10 \%$ for good (-1.0 SD or higher), 50\% for intermediate (between -1.5 and -1.0 SD), and $100 \%$ for poor performance (MMSE-KC scores below -1.5 SD of the norm) on the MMSE-KC in a phase II clinical diagnostic study. In that study, of the 1673 subjects, 351 (20.98\%) were diagnosed as having dementia. Another similarly designed study 20 performed in the Seoul metropolitan area reported an incidence of dementia of about $18.43 \%$. Because our sample consisted entirely of people with MMSE-KC scores lower than -1.5 $\mathrm{SD}$ of the norm, we could not compare these results directly, but it is reasonable to assume that the prevalence in our population would be similar to that in previous research.

In general, old age, female sex, lower education level, presence of depression, traumatic brain injury, and other vascular risk factors are well-known risk factors and correlates of dementia. $^{21}$

In the present study, multivariate analysis revealed that advanced age, no education, living in a nursing home, and depression were correlated with dementia. Marital status, economic status, and urban/rural residence were not associated with dementia after controlling for age, sex, education level, depression, traumatic brain injury, and number of medical illnesses.

Age is an established risk factor for dementia, and the prevalence of dementia increases with age. ${ }^{22-24}$ Our results concur with previous results, demonstrating that older age is a risk fac- 
Table 2. Prevalence of dementia according to levels of variables and crude odds ratios and age and sex adjusted odds ratios

\begin{tabular}{|c|c|c|c|c|c|c|c|c|c|c|c|c|c|}
\hline & & \multicolumn{2}{|c|}{ Men } & \multicolumn{2}{|c|}{ Women } & \multicolumn{2}{|c|}{ Total } & \multirow{2}{*}{ COR } & \multicolumn{2}{|c|}{$95 \% \mathrm{CI}$} & \multirow{2}{*}{ ASOR } & \multicolumn{2}{|c|}{$95 \%$ CI } \\
\hline & & $\mathrm{N}$ & $\%$ & $\mathrm{~N}$ & $\%$ & $\mathrm{~N}$ & $\%$ & & Upper & Lower & & Upper & Lower \\
\hline Total & & 72 & 17.3 & 246 & 21.7 & 318 & 20.5 & & & & & & \\
\hline \multirow[t]{5}{*}{ Age } & $65-69$ & 11 & 16.7 & 17 & 13.7 & 28 & 14.7 & & & & & & \\
\hline & $70-74$ & 25 & 18.2 & 27 & 13.4 & 52 & 15.4 & 1.052 & 0.639 & 1.731 & 1.057 & 0.642 & 1.741 \\
\hline & $75-79$ & 17 & 13.2 & 49 & 19.3 & 66 & 17.2 & 1.201 & 0.742 & 1.942 & 1.204 & 0.744 & 1.947 \\
\hline & $80-84$ & 11 & 25.6 & 65 & 25.7 & 76 & 25.7 & 1.999 & 1.239 & 3.225 & 1.963 & 1.212 & 3.179 \\
\hline & $85+$ & 8 & 19.0 & 88 & 29.2 & 96 & 28.0 & 2.272 & 1.427 & 3.617 & 2.204 & 1.378 & 3.526 \\
\hline \multirow[t]{3}{*}{ Education } & 7 years+ & 28 & 15.5 & 3 & 4.3 & 31 & 12.4 & & & & & & \\
\hline & 1-6 years & 26 & 15.1 & 37 & 12.8 & 63 & 13.7 & 1.121 & 0.707 & 1.777 & 1.157 & 0.715 & 1.873 \\
\hline & None & 18 & 28.1 & 205 & 26.5 & 223 & 26.6 & 2.569 & 1.712 & 3.855 & 2.621 & 1.606 & 4.277 \\
\hline \multirow[t]{2}{*}{ Residency } & Urban & 31 & 14.1 & 85 & 19.9 & 116 & 17.9 & & & & & & \\
\hline & Rural & 37 & 19.6 & 156 & 22.6 & 193 & 21.9 & 1.277 & 0.989 & 1.65 & 1.123 & 0.862 & 1.464 \\
\hline \multirow{4}{*}{$\begin{array}{l}\text { Living } \\
\text { arrangement }\end{array}$} & With spouse & 33 & 12.7 & 39 & 17.4 & 72 & 14.9 & & & & & & \\
\hline & With others & 6 & 20.0 & 62 & 25.2 & 68 & 24.6 & 1.866 & 1.288 & 2.705 & 1.470 & 0.982 & 2.201 \\
\hline & Alone & 9 & 11.4 & 82 & 15.6 & 91 & 15.1 & 1.022 & 0.731 & 1.428 & 0.794 & 0.548 & 1.149 \\
\hline & Nursing home & 23 & 47.9 & 59 & 45.4 & 82 & 46.1 & 4.876 & 3.312 & 7.178 & 3.969 & 2.649 & 5.947 \\
\hline \multirow[t]{3}{*}{ Marital status } & Married & 40 & 14.9 & 45 & 19.6 & 85 & 17.1 & & & & & & \\
\hline & Bereaved & 18 & 19.1 & 187 & 22.3 & 205 & 21.9 & 1.376 & 1.04 & 1.821 & 1.014 & 0.731 & 1.408 \\
\hline & Others & 13 & 24.1 & 13 & 21.0 & 26 & 22.4 & 1.407 & 0.858 & 2.308 & 1.359 & 0.823 & 2.242 \\
\hline \multirow[t]{2}{*}{ Economic status } & Not disadvantaged & 4 & 12.9 & 5 & 21.7 & 9 & 16.7 & & & & & & \\
\hline & Disadvantaged & 67 & 17.4 & 239 & 21.7 & 306 & 20.6 & 1.299 & 0.628 & 2.686 & 1.028 & 0.492 & 2.151 \\
\hline \multirow[t]{2}{*}{ Head trauma } & No & 70 & 16.9 & 245 & 21.6 & 315 & 20.4 & & & & & & \\
\hline & Yes & 2 & 50.0 & 1 & 100.0 & 3 & 60.0 & 5.843 & 0.972 & 35.12 & 6.210 & 1.022 & 37.744 \\
\hline \multirow[t]{2}{*}{ Depression } & No & 53 & 15.5 & 194 & 21.5 & 247 & 19.8 & & & & & & \\
\hline & Yes & 19 & 25.3 & 52 & 22.7 & 71 & 23.4 & 1.229 & 0.91 & 1.658 & 1.258 & 0.929 & 1.703 \\
\hline \multirow{4}{*}{$\begin{array}{l}\text { No. medical } \\
\text { illness }\end{array}$} & 0 & 19 & 18.6 & 58 & 21.6 & 77 & 20.8 & & & & & & \\
\hline & 1 & 20 & 16.9 & 70 & 21.3 & 90 & 20.2 & 0.95 & 0.676 & 1.335 & 0.959 & 0.679 & 1.355 \\
\hline & 2 & 13 & 16.9 & 38 & 23.5 & 51 & 21.3 & 1.019 & 0.685 & 1.517 & 1.071 & 0.715 & 1.604 \\
\hline & $3-5$ & 3 & 16.7 & 10 & 27.8 & 13 & 24.1 & 1.191 & 0.608 & 2.332 & 1.337 & 0.676 & 2.648 \\
\hline
\end{tabular}

ASOR: Age and Sex Adjusted, In case of Age: sex-adjusted odd ratio. COR: crude odd ratios, CI: confidence interval

tor for dementia among those with lower MMSE-KC scores.

Many studies have found higher rates of dementia among women. ${ }^{22,23,25,26}$ This is usually explained by a life of cumulative social disadvantages; for example, a lack of educational opportunities in early life, which severely hinders access to employment and personal development. Lower educational attainment and less complex occupational activities have been found to be associated with cognitive decline and dementia risk. ${ }^{27,28}$ Our results in this area are not consistent with previous results, but this difference could be explained by differences in the characteristics of subject populations. Gender may be an important modifier of the risk for $\mathrm{AD}$, and this may be due to biological differences, ${ }^{29}$ differences in survival rates, or cohort differenc- es in behavior and exposure. ${ }^{30}$ Our subject population was not a general population but a group already at risk for cognitive decline (lower MMSE-KC score). Our results may also be explained by the unequal proportions of men and women and variation in their characteristics. The sample included more women. Furthermore, men are more likely to live with their spouse than are women, who are more likely to live alone. This means that female subjects may have better social function than men, who are considered dependent on their spouses throughout their lives.

De Deyn et al. ${ }^{31}$ suggested that the higher prevalence of dementia in women than in men is partly because men who are starting to show cognitive decline may be less capable of man- 
Table 3. Multiple logistic regression analysis of dementia and related variables

\begin{tabular}{|c|c|c|c|c|c|c|c|}
\hline & \multirow{2}{*}{ B } & \multirow{2}{*}{ SE } & \multirow{2}{*}{ Wald } & \multirow{2}{*}{$\mathrm{p}$-value } & \multirow{2}{*}{ OR } & \multicolumn{2}{|c|}{$95.0 \% \mathrm{CI}$} \\
\hline & & & & & & Upper & Lower \\
\hline Constants & -1.627 & 0.501 & 10.567 & 0.001 & 0.196 & & \\
\hline \multicolumn{8}{|l|}{ Sex } \\
\hline Women & -0.111 & 0.244 & 0.208 & 0.648 & 0.895 & 0.555 & 1.443 \\
\hline \multicolumn{8}{|l|}{ Age } \\
\hline $65-69$ & & & 19.087 & 0.001 & & & \\
\hline $70-74$ & -0.196 & 0.322 & 0.370 & 0.543 & 0.822 & 0.437 & 1.545 \\
\hline $75-79$ & 0.047 & 0.311 & 0.023 & 0.881 & 1.048 & 0.570 & 1.927 \\
\hline $80-84^{*}$ & 0.757 & 0.309 & 5.989 & 0.014 & 2.132 & 1.163 & 3.908 \\
\hline $85+*$ & 0.674 & 0.312 & 4.677 & 0.031 & 1.963 & 1.065 & 3.617 \\
\hline \multicolumn{8}{|l|}{ Education (years) } \\
\hline 7 years + & & & 11.001 & 0.004 & & & \\
\hline $1-6$ years & 0.073 & 0.295 & 0.062 & 0.804 & 1.076 & 0.604 & 1.918 \\
\hline None* & 0.731 & 0.304 & 5.780 & 0.016 & 2.078 & 1.145 & 3.771 \\
\hline \multicolumn{8}{|l|}{ Residence } \\
\hline Rural & -0.119 & 0.172 & 0.477 & 0.490 & 0.888 & 0.634 & 1.244 \\
\hline \multicolumn{8}{|c|}{ Living arrangement } \\
\hline With spouse & & & 48.689 & 0.000 & & & \\
\hline With others & 0.636 & 0.527 & 1.454 & 0.228 & 1.888 & 0.672 & 5.306 \\
\hline Alone & -0.005 & 0.518 & 0.000 & 0.993 & 0.995 & 0.361 & 2.748 \\
\hline Nursing home* & 1.728 & 0.501 & 11.877 & 0.001 & 5.630 & 2.107 & 15.044 \\
\hline \multicolumn{8}{|l|}{ Marital status } \\
\hline Married & & & 0.972 & 0.615 & & & \\
\hline Bereaved & -0.489 & 0.496 & 0.972 & 0.324 & 0.613 & 0.232 & 1.622 \\
\hline Others & -0.436 & 0.562 & 0.600 & 0.439 & 0.647 & 0.215 & 1.948 \\
\hline \multicolumn{8}{|l|}{ Economic status } \\
\hline Disadvantaged & -0.431 & 0.405 & 1.132 & 0.287 & 0.650 & 0.293 & 1.438 \\
\hline \multicolumn{8}{|c|}{ Head trauma history } \\
\hline Positive & 0.417 & 1.273 & 0.107 & 0.744 & 1.517 & 0.125 & 18.389 \\
\hline \multicolumn{8}{|l|}{ Depression } \\
\hline Positive* & 0.461 & 0.192 & 5.778 & 0.016 & 1.586 & 1.089 & 2.309 \\
\hline \multicolumn{8}{|c|}{ Number of medical illness } \\
\hline 0 & & & 0.189 & 0.979 & & & \\
\hline 1 & -0.081 & 0.189 & 0.183 & 0.669 & 0.922 & 0.637 & 1.335 \\
\hline 2 & -0.032 & 0.221 & 0.021 & 0.886 & 0.969 & 0.628 & 1.495 \\
\hline 3 and over & -0.055 & 0.379 & 0.021 & 0.885 & 0.947 & 0.451 & 1.989 \\
\hline
\end{tabular}

*statistically significant. OR: odds ratio, CI: confidence interval

aging their lives and therefore prefer institutionalization. As nearly all previous epidemiological studies failed to include residents of nursing homes, rest homes, or other specializedcare facilities, they would have missed a portion of the population in whom cognitive deterioration is more likely. This may result in a gender bias, as this group may contain relatively more men. Our study included institutionalized persons, and this may have resulted in the contrast between our finding of no higher dementia prevalence in women and others' results showing a higher prevalence. A metaanalysis done by Gao et $\mathrm{al}^{32}$ found gender differences in the incidence of dementia associated with $\mathrm{AD}$ but not in the incidence of dementia in general. These differences are most likely explained by the fact that men are at a higher risk than women for vascular dementia. 
Our study did not separate $\mathrm{AD}$ and dementia, so our result is partially consistent with that of Gao et al. ${ }^{32}$

Recently, there has been conflicting evidence regarding gender differences in dementia risk. In a recent metaanalysis, gender was independently associated with dementia risk in all regions other than North America and Pacific Asia. ${ }^{33}$ In the present study, gender was not a correlate of dementia in univariate or multivariate analysis. According to Kim et al., gender differences in mental health are often attributed to gender-related differences in social exposure. ${ }^{34}$ Over the past few decades, however, rapid social and economic changes, such as the expansion of formal education and of women's participation in the labor force, have had profound implications for Korean women. ${ }^{35}$ This may have also contributed to our results.

Multivariate analyses showed that education was strongly associated with dementia. Lower education level is a well-known risk factor for dementia, and our result supports previous findings in this regard. ${ }^{30,36-38}$ The subjects of our research were at risk for cognitive decline, and even among this population, education was, irrespective of gender, powerfully correlated with dementia. This result suggests that, even in the case of groups at risk for cognitive decline, lower education level could be related to the development of dementia. This is also partially in accord with previous research ${ }^{39}$ suggesting that highly educated individuals show fewer clinical symptoms of dementia than do less educated individuals, ${ }^{40,41}$ and other research has suggested that highly educated persons, who have greater cognitive reserve, may demonstrate more efficient or flexible use of brain networks and cognitive paradigms. ${ }^{42}$ Intellectually challenging activities, such as those involved in education and other complex mental activities, are recognized as playing a significant role in maintaining or enhancing brain reserve and thus providing protection against the risk of dementia in old age. ${ }^{36}$

Depression was not significantly associated with dementia in the univariate analysis, but after controlling for multiple confounding factors, depression was found to be independently correlated with dementia. This result is consistent with previous cross-sectional $\mathrm{l}^{43-45}$ and longitudinal studies ${ }^{46-48}$ and metaanalyses ${ }^{49}$ suggesting that depressive symptoms are common in older persons and are associated with cognitive impairment and dementia, especially $\mathrm{AD}$, among the general population.

In fact, the relationship between depression and dementia is much more complex. Researchers have suggested two possibilities: depressive symptomatology may be a risk factor for dementia or, as several investigators have hypothesized, ${ }^{47,48,50}$ depression may be an early sign of the disease rather than an independent risk factor.

Recently, a co-twin control analysis found that the increased likelihood of dementia associated with depression may not be attributable to shared genes or shared early life influences, showing that a twin who had a history of depression was three times more likely to have dementia compared to his or her cotwin. Wilson et al. ${ }^{46}$ suggested that the association of depressive symptoms with clinical $\mathrm{AD}$ appears to be independent of cortical plaques and tangles. Other researchers have highlighted the effects of depression on hippocampal formation or on the hypothalamo-pituitary-adrenal axis. ${ }^{51}$

We were unable to determine causality due to the cross-sectional design of our study, but our results indicate that the presence of depression in a high-risk group may further influence the development of dementia.

In Korea, nursing homes are usually for persons who are in cognitive decline and who have no support system. Our results showed that living in a nursing home was the strongest predictor of dementia. This strong association may be due to the characteristics of the 194 nursing home residents in our study, who had MMSE-KC scores below -1.5 SD relative to the norm, and $46.1 \%$ of whom had already been diagnosed with dementia.

In contrast to previous studies, ${ }^{52-56}$ a history of head trauma was not associated with dementia in the present study. The univariate analysis showed an association, but the multivariate analysis did not. Previous studies suggested that this association could be due to increases in $A \beta$ pathology ${ }^{57}$ and tau pathology in brain tissue. Cerebrospinal fluid $A \beta$ levels are elevated, and APP is overproduced after brain injury. ${ }^{58}$ On the other hand, this association may be attributable to selective recall bias, as many prospective studies have failed to find a significant association between dementia and head trauma. ${ }^{59}$ Our sample included only five persons with head trauma history, and thus selection bias could also have led to our negative result.

Whether marital status is a correlate of dementia remains controversial, but non-married status (including widowed/widower/unmarried) has been accepted as a risk factor for developing dementia in some studies. Our analysis did not show marital status to be a significant risk factor, a finding that is consistent with a previous Korean study. ${ }^{9}$ Some, but not many, studies among Asians have found that widowed/unmarried individuals are at risk for dementia, and this may reflect a better social support system among married subjects. However, this correlation has not been found in other studies, and the association requires further clarification. ${ }^{18,60}$

The question of whether living in a rural area is correlated with dementia is also controversial at this time. Although our results showed that living arrangement was correlated with dementia, the association was not quite significant $(\mathrm{p}=0.061)$. This finding corresponds to findings from a previous Korean study ${ }^{9}$ and a Western study, ${ }^{18}$ but is not consistent with another study. ${ }^{61}$ This inconsistency among studies could be explained by group and racial differences and, especially, by characteristics of Jeju Island's population, which cannot be easily differentiated into 
urban and rural areas in many respects. For example, the main economic activity is centered in urban areas but also includes farming activities that could be classified as rural. However, the fact that all of our subjects had low MMSE-KC scores could reduce the impact of rural living on the risk of dementia.

Economic status is a well-known risk factor for dementia, ${ }^{31}$ and the usual explanation is that poor economic status is likely related to lower education level. However, our results did not reveal the same associations. This is likely due to the homogenous characteristics of our group, that is, the NEDDP included only persons of low socioeconomic status.

Multivariate analysis found that the number of medical illness was not a correlate of dementia in our study. Generally, higher medical comorbidity is significantly associated with lower cognitive functioning on the MMSE, taking into account age, gender, education, and care setting. ${ }^{62}$ Higher medical comorbidity is also significantly associated with poorer self-care, decreased mobility, and greater incontinence, adjusted for the same demographic factors and for cognitive functioning. Thus, medical comorbidities are implicated in cognitive decline, and they may also adversely affect function and independence independent of cognitive status. The discrepancy between previous studies and our results could be explained by group differences. That is, our subjects were already characterized by cognitive decline, poor socioeconomic status, and poor social support.

This study has some limitations. First, non-responders may have had poorer health status than responders, which may have resulted in an underestimation of the prevalence of dementia. Second, the failure to consider certain known dementia risk factors, such as the apolipoprotein E genotype, smoking, obesity, diabetes, vascular factors, and behavioral symptoms, means that many confounding factors were not considered. Third, since all participants of this research were recipients of financial supports, it is hard to apply to the general population. Fourth, this study was also limited by its cross-sectional nature which made it impossible to determine causal relationships between correlates and dementia.

Despite some limitations, this study has several strengths. This is the first study of this specific population, including a sizeable sample over the age of 85 as well as long-term care residents. In addition, we were able to minimize diagnostic variability, as all research geropsychiatrists were certified for CERAD-K assessment through formal training programs provided by the CERAD-K headquarters.

In conclusion, the prevalence of dementia was very high among older people with low MMSE-KC scores, and older age, no education, nursing home residence, and depression were significant correlates. Enhancing lifetime education by providing intellectually challenging activities as a means to improve cognitive reserve, encouraging living at home rather than in a nursing home, and preventing and treating depression in the early phase could reduce dementia prevalence in this group.

\section{Acknowledgments}

This work was supported by the research grant from the Hyocheon Academic Research Fund of the Cheju National University in 2009.

\section{REFERENCES}

1. Korea Statistics Office: Internal migration statistics 2005. Available at: http://meta.nso.go.kr/metaSearch/metasearch1.jsp?josa_id=38\&is_ v=y. Accessed May 14, 2009.

2. Korea Statistics Office: Population projections for Korea 2005. Available at: http://meta.nso.go.kr/metaSearch/metasearch1.jsp?josa id=39\&juki_id=5644. Accessed May 14, 2009.

3. OECD (Organisation for Economic Co-operation and Development). Economic Survey of Korea 2005. Paris: OECD; 2005.

4. Statistics Korea. Report on the Population and Housing Census. Daejeon: Statistics Korea; 2005, p. 7-53.

5. United Nations. World Population Prospects 2006. Available at: http:// www.un.org/esa/population/publications/wpp2006/wp p2006.htm. Accessed June 30, 2007.

6. Suh GH. Dementia in Korea: trend and projection. J Korean Geriatr Psychiatry 2002;6:79-87.

7. Ernst RL, Hay JW. The US economic and social costs of Alzheimer's disease revisited. Am J Public Health 1994;84:1261-1264.

8. Kang IO, Park JY, Lee YK, Suh SR, Kim KH, Choi SJ. Analysis of Socioeconomic Costs for Dementia Patients Using Dementia Claim Database of KNHI and NMA. Seoul: National Health Insurance Corporation; 2005.

9. Kim KW, Park JH, Kim MH, Kim MD, Kim BJ, Kim SK, et al. A nationwide survey on the prevalence of dementia and mild cognitive impairment in South Korea. J Alzheimers Dis 2011;23:281-291.

10. Alzheimer's Association. 2010 Alzheimer's disease facts and figures. Alzheimers Dement 2010;6:158-194.

11. World Bank. 2006 World Development Indicators (WDI). Washington, D.C: World Bank Publications, 2007, p. 20-23.

12. Sorensen S, Duberstein P, Gill D, Pinquart M. Dementia care: mental health effects, intervention strategies, and clinical implications. Lancet Neurol 2006;5:961-973.

13. Kim MD, Hong SC, Lee CI, Kim SY, Kang IO, Lee SY. Caregiver burden among caregivers of Koreans with dementia. Gerontology 2009;55: 106-113.

14. Lee JH, Lee KU, Lee DY, Kim KW, Jhoo JH, Kim JH, et al. Development of the Korean version of the Consortium to Establish a Registry for Alzheimer's Disease Assessment Packet (CERAD-K): clinical and neuropsychological assessment batteries. J Gerontol B Psychol Sci Soc Sci 2002;57:P47-P53.

15. Lee DY, Lee KU, Lee JH, Kim KW, Jhoo JH, Kim SY, et al. A normative study of the CERAD neuropsychological assessment battery in the Korean elderly. J Int Neuropsychol Soc 2004;10:72-81.

16. American Psychiatric Association. Diagnostic Criteria from DSM-IV. Washington, D.C.: American Psychiatric Association; 1994.

17. Bae JN, Cho MJ. Development of the Korean version of the Geriatric Depression Scale and its short form among elderly psychiatric patients. J Psychosom Res 2004;57:297-305.

18. Hamid TA, Krishnaswamy S, Abdullah SS, Momtaz YA. Sociodemographic risk factors and correlates of dementia in older Malaysians. Dement Geriatr Cogn Disord 2010;30:533-539.

19. Wimo A, Winblad B, Aguero-Torres H, von Strauss E. The magnitude of dementia occurrence in the world. Alzheimer Dis Assoc Disord 2003; 17:63-67.

20. Lee DY, Lee JH, Ju YS, Lee KU, Kim KW, Jhoo JH, et al. The prevalence of dementia in older people in an urban population of Korea: the Seoul 
study. J Am Geriatr Soc 2002;50:1233-1239.

21. Richards SS SR. Family History of AD. In: Sadock BJ, Sadock VA, Ruiz P, Editors. Comprehensive Textbook of Psychiatry, 9th Edition. Philadelphia: Lippincot Williams \& Wilkins, 2009, p. 1167-1168.

22. Gussekloo J, Heeren TJ, Izaks GJ, Lighthart GJ, Rooijmans HG. A community based study of the incidence of dementia in subjects aged 85 years and over. J Neurol Neurosurg Psychiatry 1995;59:507-510.

23. Kim JM, Stewart R, Prince M, Shin IS, Yoon JS. Diagnosing dementia in a developing nation: an evaluation of the GMS-AGECAT algorithm in an older Korean population. Int J Geriatr Psychiatry 2003;18:331336.

24. Kua EH. Dementia in elderly Malays--preliminary findings of a community survey. Singapore Med J 1993;34:26-28.

25. Krishnaswamy S, Kadir K, Ali RA, Sidi H, Mathews S. Prevalence of dementia among Malaysia in an urban settlement in Malaysia. Neurol J Southeast Asia 1997;2:159-162.

26. Lobo A, Saz P, Marcos G, Día JL, De-la-Cámara C, Ventura T, et al. The ZARADEMP Project on the incidence, prevalence and risk factors of dementia (and depression) in the elderly community: II. Methods and first results. Eur J Psychiatry 2005;19:40-54.

27. Whalley LJ, Dick FD, McNeill G. A life-course approach to the aetiology of late-onset dementias. Lancet Neurol 2006;5:87-96.

28. Ngandu T, von Strauss E, Helkala EL, Winblad B, Nissinen A, Tuomilehto J, et al. Education and dementia: what lies behind the association? Neurology 2007;69:1442-1450.

29. Goodman Y, Bruce AJ, Cheng B, Mattson MP. Estrogens attenuate and corticosterone exacerbates excitotoxicity, oxidative injury, and amyloid beta-peptide toxicity in hippocampal neurons. J Neurochem 1996;66: 1836-1844.

30. Launer LJ, Andersen K, Dewey ME, Letenneur L, Ott A, Amaducci LA, et al. Rates and risk factors for dementia and Alzheimer's disease: results from EURODEM pooled analyses. EURODEM Incidence Research Group and Work Groups. European Studies of Dementia. Neurology 1999;52:78-84.

31. De Deyn PP, Goeman J, Vervaet A, Dourcy-Belle-Rose B, Van Dam D, Geerts E. Prevalence and incidence of dementia among 75-80-year-old community-dwelling elderly in different districts of Antwerp, Belgium: the Antwerp Cognition (ANCOG) Study. Clin Neurol Neurosurg 2011; 113:736-745.

32. Gao S, Hendrie HC, Hall KS, Hui S. The relationships between age, sex, and the incidence of dementia and Alzheimer disease: a metaanalysis. Arch Gen Psychiatry 1998;55:809-815.

33. ADI.Global Prevalence of Dementia. In: Martin P JJ, Editor. Alzheimer's Disease International, 2009, p. 25-46.

34. Jeon GS, Jang SN, Rhee SJ, Kawachi I, Cho SI. Gender differences in correlates of mental health among elderly Koreans. J Gerontol B Psychol Sci Soc Sci 2007;62:S323-S329.

35. Palley ML. Women's status in South Korea: tradition and change. Asian Survey 1990;30:1136-1153.

36. Valenzuela MJ, Sachdev P. Brain reserve and dementia: a systematic review. Psychol Med 2006;36:441-454.

37. Mortimer JA, Snowdon DA, Markesbery WR. Head circumference, education and risk of dementia: findings from the Nun Study. J Clin Exp Neuropsychol 2003;25:671-679.

38. Letenneur L, Launer LJ, Andersen K, Dewey ME, Ott A, Copeland JR, et al. Education and the risk for Alzheimer's disease: sex makes a difference. EURODEM pooled analyses. EURODEM Incidence Research Group. Am J Epidemiol 2000;151:1064-1071.

39. Roe CM, Xiong C, Miller JP, Morris JC. Education and Alzheimer disease without dementia: support for the cognitive reserve hypothesis. Neurology 2007;68:223-228.

40. Stern Y, Tang MX, Denaro J, Mayeux R. Increased risk of mortality in Alzheimer's disease patients with more advanced educational and oc- cupational attainment. Ann Neurol 1995;37:590-595.

41. Stern Y. What is cognitive reserve? Theory and research application of the reserve concept. J Int Neuropsychol Soc 2002;8:448-460.

42. Stern Y. The concept of cognitive reserve: a catalyst for research. J Clin Exp Neuropsychol 2003;25:589-593.

43. Burt DB, Zembar MJ, Niederehe G. Depression and memory impairment: a meta-analysis of the association, its pattern, and specificity. Psychol Bull 1995;117:285-305.

44. Rabbitt P, Donlan C, Watson P, McInnes L, Bent N. Unique and interactive effects of depression, age, socioeconomic advantage, and gender on cognitive performance of normal healthy older people. Psychol Aging 1995;10:307-313.

45. Teri L, Wagner A. Alzheimer's disease and depression. J Consult Clin Psychol 1992;60:379-391.

46. Wilson RS, Barnes LL, Mendes de Leon CF, Aggarwal NT, Schneider JS, Bach J, et al. Depressive symptoms, cognitive decline, and risk of $\mathrm{AD}$ in older persons. Neurology 2002;59:364-370.

47. Berger AK, Fratiglioni L, Forsell Y, Winblad B, Backman L. The occurrence of depressive symptoms in the preclinical phase of $\mathrm{AD}$ : a population-based study. Neurology 1999;53:1998-2002.

48. Devanand DP, Sano M, Tang MX, Taylor S, Gurland BJ, Wilder D, et al. Depressed mood and the incidence of Alzheimer's disease in the elderly living in the community. Arch Gen Psychiatry 1996;53:175-182.

49. Jorm AF. History of depression as a risk factor for dementia: an updated review. Aust N Z J Psychiatry 2001;35:776-781.

50. Chen P, Ganguli M, Mulsant BH, DeKosky ST. The temporal relationship between depressive symptoms and dementia: a community-based prospective study. Arch Gen Psychiatry 1999;56:261-266.

51. Reitz C, Brayne C, Mayeux R. Epidemiology of Alzheimer disease. Nat Rev Neurol 2011;7:137-152.

52. Mayeux R, Ottman R, Maestre G, Ngai C, Tang MX, Ginsberg H, et al. Synergistic effects of traumatic head injury and apolipoprotein-epsilon 4 in patients with Alzheimer's disease. Neurology 1995;45:555-557.

53. Rasmusson D, Brandt J, Martin D, Folstein M. Head injury as a risk factor in Alzheimer's disease. Brain Inj 1995;9:213-219.

54. Schofield PW, Tang M, Marder K, Bell K, Dooneief G, Chun M, et al. Alzheimer's disease after remote head injury: an incidence study. J Neurol Neurosurg Psychiatry 1997;62:119-124.

55. Fleminger S, Oliver DL, Lovestone S, Rabe-Hesketh S, Giora A. Head injury as a risk factor for Alzheimer's disease: the evidence 10 years on; a partial replication. J Neurol Neurosurg Psychiatry 2003;74:857-862.

56. Mortimer JA, van Duijn CM, Chandra V, Fratiglioni L, Graves AB, Heyman A, et al. Head trauma as a risk factor for Alzheimer's disease: a collaborative re-analysis of case-control studies. EURODEM Risk Factors Research Group. Int J Epidemiol 1991;20(Suppl 2):S28-S35.

57. Hartman RE, Laurer H, Longhi L, Bales KR, Paul SM, McIntosh TK, et al. Apolipoprotein E4 influences amyloid deposition but not cell loss after traumatic brain injury in a mouse model of Alzheimer's disease. J Neurosci 2002;22:10083-10087.

58. Franz G, Beer R, Kampfl A, Engelhardt K, Schmutzhard E, Ulmer H, et al. Amyloid beta 1-42 and tau in cerebrospinal fluid after severe traumatic brain injury. Neurology 2003;60:1457-1461.

59. Youn JC, Lee DY, Kim KW, Woo JI. Epidemiology of dementia. Psychiatry Invest 2005;2:28-39.

60. Poddar K, Kant S, Singh A, Singh TB. An epidemiological study of dementia among the habitants of eastern Uttar Pradesh, India. Ann Indian Acad Neurol 2011;14:164-168.

61. Gureje O, Ogunniyi A, Kola L, Abiona T. Incidence of and risk factors for dementia in the Ibadan study of aging. J Am Geriatr Soc 2011;59: 869-874.

62. Doraiswamy PM, Leon J, Cummings JL, Marin D, Neumann PJ. Prevalence and impact of medical comorbidity in Alzheimer's disease. J Gerontol A Biol Sci Med Sci 2002;57:M173-M177. 